\title{
QUÉ SALIÓ MAL: EL CORONAVIRUS Y EL MUNDO DESPUÉS DEL PARE TOTAL*
}

Carlo Caduff

* DOI: https://doi.org/10.18601/01245996.v23n44.07. Recepción: 15-052020, aceptación: 27-11-2020. Sugerencia de citación: Caduff, C. (2021). Qué salió mal: el coronavirus y el mundo después del pare total. Revista de Economía Institucional, 23(44), 143-169. Este artículo se publicó en Medical Anthropology Quarterly. O(0), 1-21. Traducción de Alberto Supelano; se publica con autorización del autor.

a Profesor asociado en el Departamento de Salud Global y Medicina Social del King's College de Londres, Reino Unido, [carlo.caduff@kcl.ac.uk]. 


\section{Qué salió mal: el coronavirus y el mundo después del pare total}

Resumen Este artículo examina la respuesta global a la pandemia de covid-19. Argumenta que es urgente ver más allá del virus para entender la verdadera gravedad de lo que está sucediendo hoy. ¿Cómo terminamos en un espacio de pensamiento, acción y sentimiento que ha normalizado los extremos y se basa en el supuesto de que la vida biológica es un valor absoluto separado de la política? El autor sugiere que el temor actual es alimentado por los modelos matemáticos de la enfermedad, las políticas de salud neoliberales, los informes nerviosos de los medios y los anhelos autoritarios.

Palabras clave: pandemias, preparación, poder, miedo; JEL: I13, E71

\section{What went wrong: Corona and the world after the full stop}

Abstract This article examines the global response to the covid-19 pandemic. It argues that we urgently need to look beyond the virus if we want to understand the real seriousness of what is happening today. How did we end up in a space of thinking, acting, and feeling that has normalized extremes and is based on the assumption that biological life is an absolute value separate from politics? The author suggests that today's fear is fueled by mathematical disease modeling, neoliberal health policies, nervous media reporting, and authoritarian longings.

Keywords: Pandemics, preparedness, power, fear; JEL: I13, E71

\section{O que deu errado: o coronavírus e o mundo após a parada total}

Resumo Este artigo examina a resposta global à pandemia covid-19. Ele argumenta que é urgente olhar além do vírus para entender a verdadeira gravidade do que está acontecendo hoje. Como acabamos em um espaço de pensamento, ação e sentimento que normalizou os extremos e se baseia no pressuposto de que a vida biológica é um valor absoluto separado da política? $\mathrm{O}$ autor sugere que o medo atual é alimentado por modelos matemáticos da doença, políticas de saúde neoliberais, relatórios nervosos da mídia e anseios autoritários.

Palavras-chave: pandemias, preparação, poder, medo; JEL: I13, E71 
Es como si la humanidad se hubiera dividido entre quienes creen en la omnipotencia humana (los que piensan que todo es posible si se sabe cómo organizar a las masas para ese fin) y aquellos para los que la impotencia se ha convertido en la experiencia más importante de su vida.

Hannah Arendt

L as medidas que los gobiernos de todo el mundo han tomado para contener la COVID-19 son masivas y sin precedentes. Debido a estas medidas la vida se ha paralizado casi por completo, con muchos países en confinamiento. Nunca en la historia de la humanidad se había hecho una intervención tan drástica en la vida de la población en nombre de la salud, a tal escala y en tan poco tiempo.

Como resultado del confinamiento más grande y quizás más riguroso del mundo, millones de asalariados han perdido su fuente de ingresos en India. Los trabajadores de la salud son atacados y expulsados de sus hogares porque son vistos como posibles propagadores de la enfermedad (Kalra y Ghoshal, 2020). Los vecindarios entran en pánico cuando aparece una ambulancia en la calle. Debido a la súbita prohibición de toda forma de transporte, los trabajadores migrantes han quedado atascados entre las ciudades donde solían trabajar y los pueblos donde vive su familia (Daniyal et al., 2020). Los pacientes con cáncer no han recibido atención médica esencial porque no pueden llegar al hospital. Los pobres, los marginados y los vulnerables son los más afectados por esas drásticas medidas que agravan las desigualdades existentes.

En Kenia, la policía impuso un toque de queda usando gases lacrimógenos y fuerza excesiva contra presuntos infractores (Namwaya, 2020). En Bangladesh, el gobierno creó una unidad especial para vigilar las redes sociales y arrestar personas por difundir "información errónea" sobre el virus (HRW, 2020). En Hungría, el parlamento aprobó una ley que permite al primer ministro Orban limitar la libertad de expresión, aplazar las elecciones y suspender normas y reglas por decreto (Gebrekidan, 2020). En India, los gobiernos estatales eximieron a las empresas del cumplimiento de las leyes laborales, incluidas las leyes de salud laboral, para estimular la economía (Sharma, 2020). En Líbano, el desplome de la moneda llevó a que el 75\% de la población requiriera ayuda alimentaria (Chulov, 2020). En Estados Unidos, más de 33 millones de personas han solicitado beneficios de desempleo (Rushe y Aratani, 2020).

Desafortunadamente, al momento de redactar este escrito, muchos aspectos de la pandemia son aún desconocidos, pese a la intensa investigación. Por ejemplo, no sabemos qué ayudó a contener el brote 
en China y, en particular, si la intervención del gobierno redujo la propagación del virus o si este decayó antes de pasar a otras poblaciones susceptibles. No lo sabemos. No obstante, muchos actores e instituciones han actuado como si lo supiesen, imponiendo medidas extremas que han afectado a miles de millones de personas y llevado a las sociedades al borde del colapso creando pobreza, hambre, miseria, deuda y desempleo.

Hoy muchos se preguntan cómo llegamos a donde estamos. ¿Cómo fue posible que un virus provocara una respuesta tan masiva, que amenaza a la sociedad y a la economía, con tan poca discusión sobre los costos y consecuencias de esas medidas extremas? ¿Por qué hay un amplio acuerdo en que la intervención agresiva para "aplanar la curva" era necesaria y justificada? Parece que en este experimento de salud pública sin precedentes no hubo un examen suficiente de sus consecuencias sociales, políticas y económicas.

Es sorprendente que no se haya tenido en cuenta el impacto de las medidas extremas que se han convertido en norma durante la pandemia en muchos lugares. La destrucción de vidas y medios de vida en nombre de la supervivencia nos atormentará durante décadas.

\section{CÓMO EMPEZÓ TODO}

E1 brote de COVID-19 parece haber comenzado en la ciudad de Wuhan, en diciembre de 2019. En enero, el gobierno chino puso en confinamiento a Wuhan y otras ciudades importantes de la provincia. Un confinamiento de 56 millones de personas "no tiene precedentes en la historia de la salud pública, y no es una recomendación de la OMS”, subrayó en ese momento el Dr. Gauden Galea, representante de la OMS en Beijing (Reuters, 2020). En otras provincias, el gobierno chino estableció medidas personalizadas, como el cierre de fábricas y escuelas, pero no el confinamiento nacional ni la restricción de movimientos para limitar la propagación de la enfermedad.

Los principales medios de comunicación de Estados Unidos calificaron la estrategia china de ciudad cerrada en Wuhan como "dura", "extrema", "severa"y "controversial", destacando que no ofrecía "garantías de éxito” (Qin et al., 2020). Un artículo de Nerw York Times señaló que "China intenta detener el brote de coronavirus usando una táctica [...] con una larga y complicada historia plagada de problemas sociales, políticos y éticos" (Levenson, 2020). Los expertos citados en el artículo calificaron el cierre de ciudades como "una empresa increíble" que sería "patentemente inconstitucional en Estados Unidos". "Ese tipo 
de cosas", dijo James Hodge, profesor de derecho, "es obviamente una respuesta excesiva”. Otro experto citado en el artículo, el historiador Howard Markel, señaló el "lado más oscuro de la cuarentena: su uso como instrumento social en vez del uso científico como instrumento médico”. En Reino Unido, los artículos periodísticos sugirieron que el gobierno chino no podría mantener la ciudad de Wuhan "cerrada indefinidamente para los negocios" (Graham, 2020).

En febrero, el virus siguió circulando y pronto apareció en otros países. En marzo, la OMS declaró que el brote de COVID-19 era una pandemia global. Pese a las críticas al enfoque chino, una versión burda y extrema del confinamiento se convirtió en la norma internacional promovida por expertos, funcionarios y medios de comunicación de todo el mundo. Y así la preocupación por "el lado oscuro de la cuarentena" se desvaneció rápidamente.

Algunos países, como Corea del Sur, se apartaron de esa norma y eligieron en cambio una intervención clásica contra enfermedades infecciosas: prueba-rastreo-aislamiento, con un enfoque muy centralizado para recopilar información de salud pública. Al enfatizar las pruebas masivas y el rastreo meticuloso de contactos para interrumpir la cadena de transmisión, los funcionarios de salud surcoreanos cerraron las escuelas y manejaron la crisis con éxito, sin confinamiento ni cierre de carreteras y pocas restricciones de movimiento. Corea del Sur aprendió de anteriores brotes de enfermedades infecciosas (del SARS, en particular), impuso un control central, usó tecnologías digitales, cuarentenas forzosas y tuvo una de las tasas de mortalidad más bajas por COVID-19. A finales de abril se habían detectado unos 10.000 casos de infección, pero solo murieron 240 personas.

Alemania desarrolló su propio protocolo de pruebas, publicado el 17 de enero por la OMS (Beaumont, 2020). Cuando se detectó el primer caso, el 28 de enero, inició pruebas masivas, el rastreo sistemático de contactos y la hospitalización temprana, así mantuvo una baja tasa de mortalidad y hospitales funcionales, incluso cuando aumentaron los casos de infección (Mohr y Datan, 2020). Los funcionarios de salud se apoyaron en una extensa red de laboratorios y pudieron hacer más de 500.000 pruebas de SARS-CoV-2 por semana (Buck, 2020). Junto a Corea del Sur, Alemania puso las pruebas y el rastreo de contactos en el centro de la respuesta.

Pese al énfasis de la OMS en las pruebas y al éxito temprano de Corea del Sur y de Alemania en la reducción de la propagación del virus, la mayoría de los países consideró que las pruebas a escala eran de baja prioridad y recurrió a una versión extrema del enfoque de 
confinamiento chino. Pero en China, el enfoque fue personalizado y regionalizado; como señaló un informe de la OMS, "las medidas de contención específicas se adaptaron al contexto de la provincia, del condado e incluso de la comunidad, a la capacidad del entorno y a la naturaleza de la transmisión de nuevos coronavirus"(OMS, 2020). E1 confinamiento se centró en las principales ciudades de la provincia más afectada, restringiendo la vida de 56 millones de personas en un país de 1.400 millones. En otras palabras, fue un confinamiento limitado que afectó al 4\% de la población del país. En contraste con la intervención personalizada y regionalmente diferenciada que buscaba minimizar el impacto socioeconómico de la respuesta, muchos otros gobiernos impusieron confinamientos nacionales que iban bastante más allá del enfoque chino de ciudades cerradas. En la práctica equivalían a toques de queda (después legalizados por leyes de emergencia).

Italia fue el primero en imponer un confinamiento/toque de queda nacional. Muchos países los siguieron; motivados en parte por las impactantes imágenes de hospitales desbordados en el norte de Italia y, en parte, por un informe del modelo de la enfermedad publicado en Reino Unido días después del anuncio del confinamiento nacional en Italia (Ferguson et al., 2020). Ese momento de conmoción y sorpresa desató una reacción en cadena en la respuesta a la pandemia. E1 horizonte cambió, lo inconcebible se hizo posible, y la vida de repente se volvió surrealista.

El modelo del Reino Unido atrajo mucha atención y provocó una sensación de urgencia que amplificó la presión política porque las cifras eran alarmantes (Ferguson, 2020). Publicado en un sitio web institucional, el informe comparó la COVID-19 con la gran pandemia de 1918, que mató a más de 50 millones de personas en todo el mundo, y sugirió, sin ninguna prueba, que el SARS-CoV-2 era "un virus con una letalidad comparable a la influenza H1N1 de 1918”. Lo más aterrador no fue tanto la letalidad del SARS-CoV-2 sino la

\footnotetext{
1 "E1 impacto global de la COVID-19 ha sido profundo, y su amenaza a la salud pública es la más grave de un virus respiratorio desde la pandemia de influenza H1N1 de 1918". "La última vez que el mundo respondió a una epidemia mundial de enfermedades emergentes de la escala de la pandemia actual, sin acceso a vacunas, fue la pandemia de influenza H1N1 de 191819”. Estas afirmaciones son engañosas, ignoran las pandemias de gripe de 1957 y 1968, la de VIH/SIDA, el ébola y muchos otros brotes de enfermedades infecciosas que han matado a millones de personas en todo el mundo sin una vacuna disponible. Por último, pero no menos importante, la cifra de la COVID-19 ni siquiera se acerca a la de la pandemia de gripe de 1918.
} 
licencia para lanzar predicciones, abandonar los estándares básicos de la ciencia y hacer afirmaciones dramáticas para atemorizar a la gente.

E1 informe predijo que la COVID-19 causaría 510.000 muertes en Reino Unido y 2,2 millones en Estados Unidos. Expuso posibles estrategias para reducir el impacto de la pandemia, pero el enfoque se centró exclusivamente en "intervenciones no farmacéuticas". No hizo referencia a las pruebas ni al rastreo de contactos. Uno de los informes más influyentes sobre la pandemia dejó sistemáticamente de lado una estrategia de salud pública de la cual se sabía que era efectiva.

De modo significativo, el informe afirmó que se centraba en la "factibilidad" de las medidas y promovió la idea de que la supresión sistemática de la transmisión funcionaría mejor; en otras palabras, los confinamientos. Pero excluyó de toda consideración las implicaciones sociales, políticas y económicas de la reclusión, señalando que "nunca antes se ha intentado una intervención de salud pública de tan larga duración con efectos tan perturbadores para la sociedad" ${ }^{2}$. Además de ignorar las pruebas y el rastreo de contactos como una estrategia posible, sin tener en cuenta las implicaciones de los confinamientos, y admitiendo que no hay una "decisión política fácil de tomar", los autores del informe se sintieron bastante seguros para decir que la "supresión" era la "opción de política preferida" y la" única estrategia viable" que todos los países debían implementar "de inmediato". Los cierres necesarios para la supresión se debían mantener "hasta que haya una vacuna" (que, según predijeron, serían "18 o más meses”).

Una versión burda, extrema y en últimas insostenible del enfoque chino se convirtió en la norma internacional. El cierre de la sociedad y de la economía hasta que hubiese un tratamiento médico preventivo disponible era la respuesta apropiada y la única manera posible de enfrentar la crisis, a pesar de sus costos y consecuencias.

Italia fue un modelo importante, pero en esencia ambivalente, que transformó el enfoque de ciudad (o provincia) cerrada en el de país cerrado. El escenario italiano era aleccionador y aterrador, pero también inspirador y motivador. Para evitar el desastre de Italia, los gobiernos se apropiaron el enfoque italiano de confinamiento masivo y restricción estricta de movimientos como una intervención válida para todos. En muchos países, incluidos Italia y Francia, el enfoque de país cerrado adoptó una forma militarizada, con el despliegue masivo de la policía para hacer cumplir las restricciones del confinamiento.

${ }^{2}$ E1 informe distingue dos estrategias, “mitigación” y "supresión”. La última corresponde ampliamente a la estrategia de confinamiento.

Revista de Economía Institucional, vol. 23 , N. ${ }^{\circ} 44$, Primer semestre/202i, Pp. I43-i69 ISSN OI $24-5996 / \mathrm{E}-$ ISSN 2346-2450 
El enfoque de país cerrado parecía obviar la necesidad de justificar una estrategia diferenciada que podría parecer desigual e injusta, y que podría intensificar los conflictos sociales y políticos a lo largo de múltiples fracturas internas y fallas internas. Para evitar las consecuencias políticas de una estrategia diferenciada, que habría requerido pruebas sistemáticas, en Europa y otros lugares los funcionarios del gobierno invocaron la imagen políticamente conveniente de una amenaza total y sugirieron que "todos estamos en el mismo barco" y que "todos estamos juntos en esto".

La idea de que los confinamientos regionales no serían posibles y que era mejor tratar el virus como una amenaza global que impactaría de modo uniforme a todas las personas evocaba la imagen de una nación unida que enfrentaba una amenaza que exigía el sacrificio de todos. Esa imagen se basó en un falso supuesto de igualdad. La solidaridad llegó a significar no el apoyo mutuo en una situación de riesgo desigual, sino la generalización de una sensación de peligro entre una población nacional percibida como cuerpo homogéneo bajo ataque. La ideología de la solidaridad nacional ante la pandemia -de poner a todos en confinamiento y tratarlos por igual- oscureció la realidad de que el confinamiento significa cosas diferentes para las distintas personas, y que no todas están igualmente expuestas o son igualmente vulnerables. El virus y el confinamiento afectaron en forma desproporcionada a quienes ya eran vulnerables por edad, clase y raza.

Las dramáticas referencias a la magnitud de la amenaza sirvieron para justificar las políticas de cierre nacional. Este enfoque uniforme extremo y sin precedentes impuesto sistemáticamente a poblaciones enteras fue impulsado por una serie de factores que prevalecían en diferentes grados en los distintos países: creciente sensación de pánico, sensacionalismo continuo de los medios, profundos anhelos autoritarios, creciente presión política para contener la propagación del virus, relatos inquietantes de hospitales desbordados que no podían hacer frente al aumento de pacientes, cálculos engañosos de mortalidad y, lo más importante, confianza en el poder de la modelación matemática de la enfermedad.

Durante la pandemia los observadores y el público han dado por supuesto que es claro lo que está sucediendo; que todos saben lo que pasa porque pueden verlo en la televisión. Pero lo que el flujo interminable de informes de los medios de comunicación sigue ocultando es el hecho de que es imposible saber qué le ocurre a una población cuando no hay pruebas sistemáticas. La falta de pruebas creó un vacío que fue llenado por la evidencia flexible de la modelación. A falta de 
datos sólidos, la modelación de la enfermedad surgió como la ciencia presuntamente mejor y la única disponible para informar la política.

La hipérbole mediática se centró en las cifras absolutas, independientes del contexto, e hizo políticamente visibles las muertes por COVID-19. La modelación flexible de la enfermedad (a menudo basada en datos derivados de virus como el de la influenza) tomó el lugar de una vigilancia epidemiológica precisa. Los artículos publicados en línea, sin una revisión cuidadosa, hacían proyecciones aterradoras y pintaban una imagen sombría. Los modelos de simulación ampliamente divulgados crearon efectos de choque que moldearon las políticas gubernamentales.

El enfoque estrecho en las cifras tuvo un papel importante en la comprensión de la magnitud de la amenaza: alimentó el temor y el pánico en ausencia de evidencia real. Se instaló un imaginario distinto, "el imaginario de un evento sin precedentes", que parecía requerir una respuesta sin precedentes (Kelly,2018). Entre los expertos y los medios de comunicación había la sensación general de que el SARS-CoV-2 era mucho más letal que la gripe. Que esta pandemia era diferente de la influenza y requería, por tanto, un enfoque distinto, basado en la tasa de letalidad, el número de muertes entre el subconjunto de personas infectadas por el SARS-CoV-2. La tasa de letalidad cumplió un papel crucial en la justificación del experimento de salud pública que se desarrolla a nuestra vista.

\section{LA FALTA DE EVIDENCIA SE OCULTÓ CON CIFRAS}

Al inicio, las estimaciones de la tasa de letalidad variaron notablemente, del 0,17\% al 17\%. En un artículo publicado en Lancet se afirmó que la tasa de letalidad podría llegar incluso al 20\% (Baud et al., 2020). A comienzos de marzo, el Director General de la OMS declaró que la tasa de letalidad del SARS-CoV-2 era del 3,4\%. Y añadió: "En comparación, la gripe estacional suele matar a mucho menos del 1\% de los infectados"3.

Sean cuales fueren las estimaciones, el hecho es que es imposible calcular la tasa de letalidad en ausencia de pruebas sistemáticas. Dada la falta de evidencia, la única afirmación científicamente válida en ese momento era decir que simplemente no sabemos cuán letal es el virus.

Al comienzo de la pandemia quedó claro que más del $40 \%$ de las personas infectadas no mostraban síntomas en el momento de la prueba (Gudbjartsson, 2020). Esto significa que un régimen de

${ }^{3}$ [https: //www.who.int/dg/speeches/detail/who-director-general-s-openingremarks-at-the-media-briefing-on-covid-19---3-march-2020]. 
vigilancia en el que solo se hacen pruebas a personas con síntomas excluye automáticamente a un gran número de infectados. Además, los pacientes con síntomas tienen mayor probabilidad de morir que las personas asintomáticas. $\mathrm{El}$ resultado es una tasa de letalidad exagerada.

Las estrategias de testeo diferían entre países y cambiaban en cada país con el tiempo. Por ejemplo, el 25 de febrero, el Ministerio de Salud italiano publicó una política revisada, que daba prioridad a los pacientes con síntomas clínicos graves (y, por tanto, con mayor posibilidad de morir). Este cambio de política dio como resultado un aumento aparente de la tasa de letalidad, del $311 \%$ el 24 de febrero al $722 \%$ el 17 de marzo (Onder et al., 2020). De repente, el virus parecía haberse vuelto mucho más letal. Pero este aumento era una ilusión numérica, un artificio estadístico. La letalidad del virus no cambió.

Hubo cambios en la política de testeo en muchos países, incluso en regiones donde se usaban diferentes tácticas para contar las muertes. En China, los pacientes asintomáticos con resultado positivo no se contaban como casos de infección (Wu et al., 2020). En Bélgica, las muertes se contaban sin hacer ninguna prueba (Schultz, 2020); del 52\% de todas las muertes, solo el 4,5\% fue confirmado como COVID-19 positivo en pruebas de laboratorio. Solo se sospechaba que casi la mitad del total de víctimas estaba ligada al virus, pero en realidad no se habían hecho pruebas.

No había acuerdo, y sigue sin haberlo, entre expertos y funcionarios sobre lo que se considera una muerte causada por el virus. En Italia, las muertes asociadas a la COVID-19 se definieron como las que ocurren en pacientes con resultado positivo en el examen, "independientemente de las enfermedades preexistentes que pueden haber causado la muerte" (Onder et al., 2020). Esto es especialmente preocupante en términos de la calidad de los datos, porque la gran mayoría de las muertes ocurren en pacientes mayores de 65 años con una o más comorbilidades. Los pacientes con resultado positivo en las pruebas que mueren por una enfermedad cardíaca o un cáncer terminal no necesariamente mueren por la infección del SARS-CoV-2. Pero aparecen en las estadísticas de algunos países. Esta confusión entre pacientes que mueren con el virus y que mueren por él afecta los datos y su calidad, y hace imposible las comparaciones entre países.

A esto cabe añadir que casi todas las pruebas que se han hecho usan pruebas de ARN, que solo pueden detectar la infección mientras el virus está presente en el cuerpo. Pero no pueden determinar si una persona tuvo el virus en el pasado. Solo las pruebas serológicas de anticuerpos contra el virus pueden dar una imagen precisa de cuántas 
personas han sido infectadas en una población dada. Pero esos estudios serológicos sistemáticos se omitían y aún se omiten.

Dada la falta de pruebas y teniendo en cuenta el sesgo de selección, el gran número de casos asintomáticos, la confusión en la definición de los casos, los cambios en las políticas de testeo y la dificultad de saber quién muere con o por la enfermedad, no se puede determinar de modo confiable el denominador para calcular las tasas de mortalidad reales. Sin un denominador es matemáticamente imposible calcular la tasa de letalidad. Pero, pese a la falta de datos, los expertos, funcionarios y medios de comunicación fueron cautivados por la supuesta claridad y confiabilidad de las cifras, y siguieron circulando estimaciones descabelladas, lo que desató un torrente de gráficos aterradores con curvas exponenciales.

En las últimas semanas de marzo se hicieron cada vez más pruebas a nivel mundial, y hoy se hacen aún más pruebas. No es sorprendente que las estimaciones de la tasa de letalidad hayan disminuido notablemente, porque el denominador aumenta debido al aumento de pruebas. En Islandia, el 12\% de la población ha sido testeado con pruebas RT-PCR, independientes de los síntomas, lo que sugiere una tasa de letalidad del $0,55 \%{ }^{4}$. Esta cifra es 6 veces menor que la estimación oficial de la OMS.

E1 Centro de Medicina Basada en la Evidencia de la Universidad de Oxford señaló que si se supone que el 1\% de la población de Islandia está infectada, la tasa de letalidad sería del 0,03\% ${ }^{5}$. Un estudio que usa pruebas RT-PCR y serológicas realizado en una de las regiones más afectadas de Alemania indicó una tasa de mortalidad del 0,37\% y una tasa de letalidad por la infección del 0,06\% (Streeck et al., 2020).

Por las epidemias y pandemias del pasado sabemos que la tasa de letalidad a menudo se sobrestima notablemente al inicio de un brote porque la detección de casos es limitada, en gran medida basada en pacientes hospitalarios y comúnmente sesgada hacia los casos más graves de la enfermedad. Cuando ocurrió la pandemia de gripe porcina H1N1 en 2009, la tasa de letalidad estimada varió entre el 0,1\% y el $5,1 \%$ en las primeras diez semanas del brote. En 2019, una década después, la OMS reportó que esta pandemia tuvo una tasa de letalidad del $0,02 \%^{6}$; es decir, la tasa de letalidad real fue cinco veces menor que la estimación más baja.

${ }^{4}$ [https://www.worldometers.info/coronavirus].

5 [https://www.cebm.net/covid-19/global-covid-19-case-fatality-rates/].

${ }^{6}$ [https://onlinelibrary.wiley.com/doi/full/10.1111/irv.12074].

Revista de Economía Institucional, vol. 23 , N. ${ }^{\circ} 44$, Primer Semestre/202i, PP. I43-i 69 ISSN OI $24-5996 / \mathrm{E}-\mathrm{ISSN} 2346-2450$ 
Los académicos de ciencias sociales han mostrado que las cifras pueden engañar. Las cifras tienen la capacidad de revelar y ocultar. Ahí reside su magia. Aparecen como portadoras de la verdad en apariencia neutrales. Dan la sensación de precisión matemática, hacen que las cosas parezcan más ciertas de lo que en realidad son y desvían la atención de las condiciones en que se produjeron. Es peligroso hacer abstracción de las limitaciones de sus condiciones de producción $y$ tratar las cifras como absolutos, porque hace comparables cosas incomparables, porque sugiere conocimiento científico donde falta evidencia, y porque crea la sensación de una gran amenaza que oculta la naturaleza diferencial del riesgo. Usar las cifras de ese modo no tiene en cuenta que no todos están en riesgo de igual manera.

\section{FRAGILIDADES ESTRUCTURALES}

Una de las cifras más interesantes de la pandemia de COVID-19 es el número de muertes por millón de habitantes por país. Esta cifra es quizá más confiable que la tasa de letalidad porque es menos probable que se omitan muertes (ignorando por ahora el caso de Bélgica y la dificultad de definir las muertes causadas por el SARS-CoV-2), y porque se conoce el denominador, la población del país ${ }^{7}$. Las muertes por millón de habitantes en cinco países al 15 de mayo de 2020 son:

España: 584

Italia: 519

Francia: 420

Alemania: 95

Corea del Sur: 5

Las asombrosas diferencias entre países no pueden ser explicadas únicamente por la demografía o las tasas de infección (algunos países parecen tener más personas infectadas por millón de habitantes que otros y, por tanto, podrían estar desbordados, aunque esto es también una cuestión de tiempo: cuántos casos por semana por región). Lo que pueden revelar las diferencias (y es necesario señalar que pueden cambiar) es que algunos sistemas de salud pueden enfrentar la crisis de mejor manera que otros. Las fragilidades estructurales de un sistema de salud con poca financiación y poco personal, sobrecargado y cada vez más privatizado y fracturado contribuyen a unas tasas de mortalidad más altas (Adams, 2020). En cierto sentido, cada sociedad tiene la mortalidad que se merece (Canguilhem, 1989, p. 161).

7 [https://www.worldometers.info/coronavirus].

Revista de Economía Institucional, vol. 23 , n.o 44 , Primer semestre/202i, pp. I43-í69 ISSN OI 24-5996/E-ISSN 2346-2450 
Donde la atención médica es de fácil acceso, con personal suficiente, bien capacitado y capacidad flexible, es más probable que los pacientes reciban mejor atención y sobrevivan. En este sentido, importa que España tenga 3 UCI por cada 1.000 habitantes, Italia 3,2 , Francia 6, Alemania 8 y Corea del Sur 12,38. Aunque el número de camas por habitante es un indicador tosco, cabe destacar que Alemania tiene más de 30.000 UCI con personal capacitado, de las cuales solo 11.500 estaban ocupadas a comienzos de abril de 2020 (MDR, 2020), cuando había más casos en Alemania que en Francia y Reino Unido, y algo menos que en España e Italia. Claramente, el de Alemania no fue un sistema de salud desbordado por un súbito aumento de pacientes. Es irónico que en el pasado organizaciones como la Ocde recriminaran al sistema de salud alemán por la "oferta excesiva" de camas de hospital y su "incapacidad" para "racionalizar la capacidad hospitalaria” (Ocde, 2013).

Esto significa que la tasa de letalidad no depende solo de la naturaleza biológica del virus y del perfil de edad y salud de la población (las personas con mayor riesgo de muerte son las de más de 65 años con una o más comorbilidades). La tasa de letalidad también depende del testeo sistemático, del rastreo meticuloso de contactos, de que haya trabajadores de la salud bien capacitados, hogares de ancianos con recursos adecuados y capacidad del sistema de salud para hacer frente a la crisis (exceso de capacidad física y capacidad de respuesta), de que se proporcione atención médica de alta calidad y, en particular, de que se mantenga un personal médico seguro y saludable. En este sentido, la pandemia expuso y seguirá exponiendo brutalmente las fallas políticas y los déficits estructurales del sistema de salud.

La situación de muchos hospitales de Italia, España y Francia es preocupante, especialmente en áreas densamente pobladas. Pero es importante entender por qué algunas de estas instituciones altamente visibles se vieron abrumadas. Lombardía, la región más afectada de Italia, ha sido durante mucho tiempo un sitio experimental para la privatización del servicio de salud: la atención centrada en la comunidad "casi ha desaparecido" (Bagnato, 2020). La falta de médicos generales, la desfinanciación y el poco énfasis en la atención comunitaria aumentaron la presión sobre los hospitales de los centros urbanos. Estos hospitales no tienen exceso de capacidad física ni capacidad de respuesta para enfrentar un aumento súbito de la demanda.

En los últimos años, los hospitales de toda Europa hicieron numerosas huelgas "los médicos y trabajadores de la salud se quejaron

${ }^{8}$ [https: //data.oecd.org/healtheqt/hospital-beds.htm].

Revista de Economía Institucional, vol. 23 , N. ${ }^{\circ} 44$, Primer semestre/202i, Pp. I43-i69 ISSN OI 24-5996/E-ISSN 2346-2450 
de los recortes de fondos, de la reducción número de camas decidida por el gobierno y de una grave falta de personal médico que creó condiciones de trabajo extremas para el personal de las salas de emergencia" (Chrisafis, 2019). Los sistemas hospitalarios de Italia, España y Francia estaban al borde del colapso incluso antes de que llegara el virus.

No es sorprendente que la demostración más patente de las contradicciones estructurales de la preparación para una pandemia bajo el neoliberalismo ocurriera en Estados Unidos. Como informaron los periódicos estadounidenses, los hospitales de todo el país aplazaron los servicios médicos regulares para liberar espacio, equipo y personal para responder a la pandemia. Cuando los pacientes empezaron a evitar los hospitales debido al miedo a la infección, se cortó drásticamente una importante fuente de ingresos, "causando enormes pérdidas que han obligado a algunos hospitales a abandonar a los trabajadores de la salud mientras se esfuerzan por tratar pacientes infectados" (Harris y Schneider, 2020). Ante una "pesadilla financiera", los hospitales llenaron sus unidades de cuidados intensivos con pacientes que no necesitaban esos cuidados para cobrar más y compensar las pérdidas financieras. Además, los administradores redujeron los salarios, despidieron a cientos de empleados y enviaron a otros con licencia no remunerada, lo que debilitó aún más el sistema de salud en medio de la respuesta a la pandemia.

Cuando aparece un nuevo virus, las cosas empiezan a desmoronarse. Cuando todos se asustan, se adoptan medidas extremas, de manera más o menos improvisada, y se inyectan billones de dólares, euros y libras a la economía para compensar la pérdida. Pero una vez pasa lo peor, la crisis normal sigue y las fragilidades estructurales se mantienen (Caduff, 2015).

\section{LA RECONSTRUCCIÓN DEL MUNDO DESPUÉS DEL PARE TOTAL}

Esta pandemia nos atormentará durante décadas, de un modo que hoy apenas podemos imaginar. La naturaleza y la escala de las intervenciones que presenciamos son asombrosas, y las consecuencias -sociales, políticas y económicas- siguen siendo imprevisibles. No hay informes sistemáticos de las implicaciones y repercusiones observadas hasta ahora, y no tenemos ni idea del número de muertes indirectas debido a los confinamientos/toques de queda, el "distanciamiento social” y el "autoaislamiento". Aún falta un plan realista que indique 
cómo podemos aprender a vivir con un virus que es improbable que desaparezca pronto (Sullivan y Chalkidou, 2020).

Entre tanto, sugiero que reformulemos la conversación sobre el coronavirus para superar la confusión y la oscuridad que impregnan esta pandemia, considerando los siguientes puntos:

\section{ORIENTACIONES}

1. La aparición de nuevos virus en la población humana es normal. Sucedió antes, y volverá a suceder.

2. Los coronavirus son comunes y circulan ampliamente en los humanos. Infectan personas y matan miles, año tras año, especialmente en invierno.

3. En todo el mundo, cada año mueren entre 300 mil y 500 mil personas por el virus de la influenza. E1 SARS-CoV-2 ha matado a 300 mil personas hasta ahora. No hay duda de que causa una grave enfermedad infecciosa, hasta ahora en el rango de mortalidad que observamos durante una grave temporada de influenza. Las principales diferencias son la velocidad de la infección, el cuadro clínico de la enfermedad y su impacto en la población de más edad, las cuales causan una alta presión de morbilidad y mortalidad que abruma a los débiles sistemas de salud sin exceso de capacidad física y con poca capacidad de reacción.

4. La pandemia de influenza de 1957 mató entre 1 y 2 millones de personas en el mundo y la de 1968, entre 2 y 4 millones. Al momento de escribir este artículo, la COVID-19 ha matado a 300.000 personas, según cifras oficiales. $\mathrm{El}$ mundo ha sido testigo de pandemias peores, que incluyen 1,3 millones de muertes por tuberculosis cada año, 770.000 por infecciones por VIH cada año y 435.000 por malaria, todas prevenibles y tratables.

5. Esta observación no significa que la influenza y la COVID-19 sean clínicamente similares o que no se deba hacer nada para contener la propagación del SARS-CoV-2 y mitigar sus consecuencias. Pero lleva a preguntar por qué el miedo y el pánico se extienden como un incendio forestal, provocando medidas tan extremas, y por qué los expertos y funcionarios gubernamentales están dispuestos a organizar un esfuerzo sin precedentes para la COVID-19, pero nunca han considerado intervenciones similares para las 300.000 a 500.000 personas que mueren cada año por la influenza. El virus de la influenza es relativamente conocido. Decir que el SARS$\mathrm{CoV}-2$ es desconocido no justifica automáticamente las medidas más extremas que el mundo jamás haya visto. 


\section{DiAgnóstico}

1. Lo que hace que esta pandemia no tenga precedentes no es el virus sino la respuesta al virus.

2. Las medidas extremas para contener la propagación del virus han provocado consecuencias extremas. Es difícil sobreestimar lo que hoy presenciamos.

3. La respuesta a la pandemia ha empujado el mundo a un espacio de fragilidad e incertidumbre. Hoy se cierne un "quizás" sobre todas las cosas (Caduff, 2015). Obnubilada por la urgencia del momento inmediato, la respuesta ha abierto la puerta para que actores e instituciones impulsen sus agendas y reordenen el mundo. En los próximos años enfrentaremos los cambios que están ocurriendo.

4. La respuesta a la enfermedad es impulsada por una fantasía de control que sobrestima y reacciona en exceso. Esta fantasía ha causado y sigue causando graves daños. Es poco realista, engañosa y destinada al fracaso. Una pandemia como esta no se puede controlar; solo se puede administrar.

5. Si seguimos usando palabras como "control", solo nos estamos preparando para la decepción. Estamos lejos de encontrar un lenguaje adecuado para enfrentar los problemas que plantea esta pandemia. Necesitamos con urgencia nuevos conceptos, pero parece que tenemos poca imaginación.

6. La urgencia de la crisis ha eximido el cumplimiento de las normas básicas de calidad de la investigación científica. Los trabajos se publican sin revisión por pares. Los argumentos se exponen sin aportar evidencia. No es sorprendente que, dada la frágil infraestructura de salud en algunos países, la rapidez parezca ser más importante que la calidad, el rigor y la integridad.

7. La "ciencia" no sometida a examen, la falta de datos, la evidencia especulativa, las opiniones firmes, la desinformación deliberada, las tasas de mortalidad exageradas, la atención de los medios durante 24 horas del día durante toda la semana y la rápida difusión de historias dramáticas en las redes sociales han llevado a malas decisiones políticas y a una gran ansiedad pública.

8. Tememos a la COVID-19, y no a la gripe. A la primera la vemos como una emergencia de salud pública y a la segunda como un hecho de la vida. Hoy entendemos una vieja idea del modo difícil: no todas las vidas ni todas las muertes son iguales. Algunas muertes son más importantes que otras, atraen más atención, provocan una respuesta mayor y movilizan más recursos. 
9. En esta pandemia parece haber arraigado la creencia de que la salud es un valor absoluto y que toda vida se debe salvar por todos los medios. Entre tanto, millones de personas mueren de gripe, tuberculosis, sida, malaria y diarrea, para no mencionar enfermedades crónicas y accidentes. Parece haber menos urgencia política para evitar estas muertes prevenibles.

10.Algunos sistemas de salud se vieron desbordados por esta pandemia. Otros no.

11.Durante décadas, los gobiernos han recortado la financiación, reducido el personal y privatizado los sistemas de salud en todo el mundo; estas tendencias agravaron el impacto de la pandemia.

12.La respuesta al SARS-CoV-2 tomó una forma particular, que convergió en medidas extremas que se convirtieron en la norma en muchos países. Caben algunas preguntas: ¿era la única forma posible de manejar la crisis?, ¿por qué una versión burda del enfoque chino se convirtió en el modelo dominante? En el núcleo de la respuesta a la pandemia estuvo y sigue estando el supuesto de que no había y no hay alternativas a las medidas extremas aplicadas a poblaciones enteras con poca consideración del costo y las consecuencias. Eso no es cierto. Como han demostrado varios países, un testeo adecuado y políticas de "distanciamiento social" menos drásticas funcionan bien para administrar la pandemia.

13.Parece que algunos funcionarios vieron la COVID-19 como una enfermedad que se podía contener. Como dijo el Director General de la OMS a comienzos de marzo, "ni siquiera hablamos de contener la gripe estacional, eso simplemente no es posible. Pero es posible para la COVID-19". Esta percepción puede haber contribuido al enfoque radicalmente diferente observado en muchos países.

14.A menudo se considera que la solución óptima es "aplanar la curva”, pero no hay garantías de que el esfuerzo para hacerlo afecte realmente a largo plazo el número total de muertes por la presencia de la enfermedad en una comunidad. En últimas, solo puede diferir ese número de muertes durante un periodo más largo y, así, reducir la presión sobre los hospitales, pero no la mortalidad general.

15.Los confinamientos nacionales no son una solución. Evitan la infección mientras están vigentes, pero mantienen susceptibles a las personas. Esto es muy preocupante en una pandemia en la que el virus se ha vuelto endémico. Una vez se levantan los confinamientos, el número de personas infectadas puede volver a aumentar más adelante. Por ello ha sido tan difícil que los países 
que adoptaron esta estrategia vuelvan a la vida normal: la estrategia no es sostenible en el largo plazo.

16.Como señaló Andrea Bagnato sobre la estrategia "quédate en casa": "La respuesta de China se destacó no por la dureza del confinamiento, sino por la efectividad para separar a los infectados de los no infectados: en poco tiempo se creó un sistema centralizado de estructuras especiales (llamadas Fangcang), donde los pacientes y sus contactos eran tratados y separados en cuatro grupos, según la gravedad. En cambio, Lombardía simplemente cerró todo. Y cada día es más claro que los principales lugares de infección no eran los espacios públicos, sino los hospitales, hogares de ancianos, sitios de trabajo y, de hecho, los hogares privados" (Bagnato, 2020).

17.En Alemania, el $86 \%$ de las personas que murieron debido a la COVID-19 tenía 70 o más años (MDR, 2020). La mayoría de los pacientes que murieron tenían una o más comorbilidades, como hipertensión, diabetes, enfermedades cardiovasculares, respiratorias crónicas o cáncer. Esto significa que la pandemia mata sobre todo a personas con una ya baja esperanza de vida. E1 asunto clave es entonces el exceso de muertes: la diferencia entre el número de muertes estadísticamente esperado y las muertes que realmente ocurren en un lapso de tiempo. No hay duda de que habrá un exceso de muertes debidas a la COVID-19, pero no es claro qué tan grande será ese número.

18.La respuesta a la pandemia ha provocado un aumento sustancial del número de personas que hoy viven con enfermedades no tratadas. La prohibición del transporte público dificulta la llegada de los pacientes y el personal a los hospitales. Los pacientes con afecciones distintas de la COVID-19 evitan ir al médico porque temen infectarse. La asistencia a servicios de urgencias se redujo sustancialmente en todo el mundo. Las referencias al cáncer disminuyeron y los servicios de detección de cáncer se detuvieron por completo. En países como India los servicios de salud rural colapsaron. Los programas esenciales de salud pública se interrumpieron; y se reasignaron muchos recursos. Esto significa que se descuida a los pacientes, que no reciben atención médica o reciben muy poca, lo que lleva a enfermedades no tratadas y a un aumento de la mortalidad.

19.Un virus causa enfermedad, no hambre. Lo que amenaza el sustento de millones de personas no es la pandemia sino la respuesta a ella. En muchos países, ricos y pobres, las tendencias son impactantes. En India, los niños mueren de hambre. Los agricultores se 
suicidan porque no pueden cultivar. Los jornaleros desocupados caen muertos después de caminar centenas de kilómetros. Los pobres, marginados y vulnerables soportan la mayor carga de la respuesta la pandemia.

20.El confinamiento es un mecanismo político, no solo para prevenir sino para redistribuir los efectos negativos. Los confinamientos alejan los efectos negativos de los puntos críticos de atención pública a lugares donde son menos visibles y presuntamente menos graves. Así, son parte integral de una necropolítica de la desigualdad.

21.Esta pandemia no solo tiene que ver con la salud, sino también con el miedo, y con los objetos que se eligen y luego forman la base y la motivación del pensamiento y la acción sistemáticos ${ }^{9}$. Sentir miedo se ha vuelto una obligación, una responsabilidad, un deber. Las personas sienten miedo no solo por lo que experimentan, sino porque se les dice que deben temer y se las alienta a habitar el mundo con temor a "cuerpos extraños" y "enemigos invisibles".

22.E1 discurso público está sumamente moralizado. Al buscar a quién culpar, los individuos son expuestos como "súper propagadores", responsables del creciente número de casos. En las redes sociales, los "guerreros del encierro" acusan a los ciudadanos por falta de patriotismo y por "no cumplir su deber" ante el peligro. En este discurso público altamente moralizado, la vida se considera un valor absoluto que puede justificar casi toda forma de intervención disciplinaria en nombre de la salud.

\section{HACIA OTRA POLÍTICA DE LA VIDA}

1. La salud pública debe estar al frente y en el centro de toda intervención contra las enfermedades infecciosas. Se debe invertir en sólidas infraestructuras de salud pública aunque no haya pandemias.

2. Un modelo matemático de la enfermedad no puede sustituir a la vigilancia epidemiológica sistemática en el terreno. E1 modo más efectivo de controlar un brote es hacer pruebas, rastrear y aislar.

\footnotetext{
9 "En estos días, a veces me encuentro deseando contraer el virus; así, al menos terminaría la agotadora incertidumbre. Una clara señal de cómo aumenta mi ansiedad es cómo me relaciono con el sueño. Hasta hace casi una semana esperaba con ansia la noche: finalmente, podía entregarme al sueño y olvidarme de los temores de mi vida diaria. Ahora es casi lo contrario: Ahora me pasa casi lo contrario: tengo miedo de dormirme pues las pesadillas me atormentan cuando duermo y hacen que me despierte aterrorizado: las pesadillas sobre la realidad que me espera" (Zizek, 2020).
} 
3. Las intervenciones deben ser escalonadas en el tiempo; deben ser dinámicas, focalizadas regionalmente y basadas en el riesgo. Todas deben tener en cuenta el impacto social, político y económico, así como el efecto indirecto sobre otras condiciones de salud. Las intervenciones que hacen esto crearán estrategias de gestión que minimicen los daños colaterales.

4. Las cifras absolutas no se pueden usar para trazar la política, solo alimentan el miedo y el pánico.

5. Los confinamientos nacionales no son una solución. Protegen a las personas temporalmente, pero también las dejan susceptibles. Una vez se eliminan las restricciones, es probable que los casos de infección aumenten nuevamente. No hay salida de la pandemia; solo hay una salida de la respuesta a ella.

6. Aun estamos en una etapa temprana para entender cómo manejar clínicamente mejor la COVID-19, como enfermedad y como factor de riesgo de poblaciones potencialmente vulnerables. Es vital encontrar mejores maneras de compartir los datos de buena calidad y las prácticas efectivas para asegurar que los sistemas de salud aprendan y se adapten rápidamente.

7. Lo que muestra esta pandemia es la falta de "preparación". Esto parecerá una sorpresa dados los miles de millones de dólares, de euros y libras que se gastaron en los últimos 15 años en preparación para pandemias, incluida la experiencia de epidemias y pandemias anteriores como el ébola y la gripe porcina. ¿Cómo puede ser que los hospitales se quedaran sin máscaras N95 en una semana? ¿A dónde fueron los miles de millones gastados en preparación? La producción subcontratada y las reservas insuficientes de equipos de protección personal ponen en riesgo a los residentes de hogares de ancianos, a los trabajadores sanitarios comunitarios y al personal de los hospitales, y debilitan aún más a los sistemas de salud.

8. Los conceptos clave de la preparación deben estar en el centro de la respuesta. Quince años de preparación para una pandemia parecen haberse evaporado en el aire durante la pandemia actual. En vez de activar los planes existentes y recurrir a conceptos como el Marco de Evaluación de la Gravedad de las Pandemias, los países impusieron un confinamiento genérico masivo, no ensayado ni comprobado, con imprevisibles repercusiones sociales, políticas y económicas (CDC, 2007).

9. El SARS-CoV-2 es menos letal que cualquier ejercicio conjetural realizado por los gobiernos y las organizaciones no gubernamentales en Europa y América para planear la preparación. Habrá 
que entender por qué los conceptos clave de la preparación se dejaron de lado en esta pandemia, pese a la atención que recibió la "preparación" y los enormes recursos que consumió durante más de una década.

10.E1 temor a la muerte es poderoso en sociedades ansiosas por reprimir la realidad ineludible de la muerte. En tal contexto, es importante aplanar la curva de la murmuración, el sentimiento y la actuación extremos. Lo que fue y siempre se necesitará con urgencia es moderación y perspectiva.

11.Es peligroso seguir participando en la competencia actual para hacer predicciones cada vez más extremas. Solo apoyará a quienes ignoraron el virus inicialmente y a quienes están más que dispuestos a culparlo hoy por el desastre. Igualmente peligroso es el populismo de aplausos a la salud pública, que deja de lado toda consideración de los costos -sociales, políticos y económicos- y de las consecuencias de las intervenciones radicales.

12.Los intentos de ocultar las fallas políticas están creciendo rápidamente. Quienes colaboran en las predicciones extremas y las lecturas apocalípticas de la situación actual solo contribuyen a ocultar las fallas de política y los problemas estructurales subyacentes responsables de muchos de los problemas actuales. En países como Reino Unido y Estados Unidos ya se intenta reinterpretar el fracaso como un éxito. No es sorprendente que los gobiernos exijan a los ciudadanos que participen en actos públicos, que demuestren unidad nacional ante el peligro y celebren la fuerza y la resolución colectivas. Aviones de combate que se elevan en el cielo y helicópteros que arrojan pétalos de rosa sobre "guerreros de primera línea” son espectáculos militares. Pero los trabajadores de la salud merecen mucho más que sentimientos patrióticos y gestos simbólicos; merecen mejores políticas de salud. Hoy es esencial cuestionar y criticar.

13.Es necesario considerar la historia de la manera en que el enfoque chino se convirtió en el modelo de confinamientos genéricos en el Norte Global y luego se exportó a los países del Sur, sobre todo en vista de las dramáticas consecuencias para millones de personas que luchan por sobrevivir sin una fuente de ingresos. Es irónico que tales confinamientos a veces fueran exigidos por gente ansiosa por criticar el autoritarismo del Estado chino. En todo el mundo, la pandemia desató anhelos autoritarios en las sociedades democráticas que permitieron que su gobierno aprovechara la oportunidad, declarara estados de excepción e impulsara su 
agenda política. Hay comentaristas que vieron la pandemia como una oportunidad para que Occidente aprenda del autoritarismo de Oriente. En esta pandemia se corre el riesgo de enseñar a la gente a amar el poder y a pedir su aplicación meticulosa.

14.El tiempo de pandemia es propicio para todo tipo de proyectos políticos.

15. Como resultado de las imprevisibles consecuencias sociales, políticas y económicas de las medidas generales actuales, los gobiernos de todos los países han anunciado proyectos de "estímulo" que cuestan billones de dólares, libras, pesos, rands y rupias. Destinados principalmente a individuos y empresas, estos proyectos de ayuda de emergencia inyectan enormes sumas de dinero a la economía, pero irónicamente no se destinan a fortalecer la infraestructura de salud pública ni a mejorar la atención médica. Los billones que los gobiernos gastan hoy en paquetes de "estímulo" superan incluso a los de la crisis financiera de 2008 y tendrán que pagarse de algún modo. Hoy se está gestando una profunda recesión global. Si las políticas de austeridad anteriores están en el origen de la crisis actual -con sistemas de salud desbordados en algunos países-, el rápido aumento de la deuda pública crea las condiciones perfectas para una mayor austeridad en el futuro. La respuesta a la pandemia tendrá graves implicaciones para la financiación pública de la educación, el bienestar, la seguridad social, el medio ambiente y la salud en el futuro.

16.Si se cree que algo bueno saldrá de esta crisis, se debería pensar de nuevo. Hoy solo vamos más rápido, en un automóvil mucho más grande, pero en la misma carretera y con el mismo destino.

\section{UN LUGAR DIFÍCIL PARA LA CRÍTICA}

Wolf Bukowski señala que la discusión política en Italia hoy está dominada por una "responsabilidad' acrítica", que no encuentra un lugar aparte del imperativo de contener el virus. "La intuición correcta de que 'no debemos cuestionar la realidad de la epidemia' se transforma muy fácilmente en 'no debemos cuestionar la respuesta del gobierno a la epidemia”' (Bukowski, 2020). En tal contexto, toda intervención de control impuesta por el Estado se considera legal, y no parecen necesarios una discusión ni un debate democráticos (“¡Dejen hablar a los expertos!”)

En otros países, la crítica se ha vuelto difícil por otras razones. La tragedia del momento político actual en Estados Unidos, Reino Unido 
y Brasil es que los políticos de derecha empujaron a muchas personas a aceptar medidas que solo parecían posibles en regímenes autoritarios. Allí, participar en el análisis crítico se ha vuelto casi imposible porque se considera que se hace el juego a Trump, Johnson y Bolsonaro, figuras políticas despreocupadas por la salud pública y las asombrosas desigualdades que afligen a nuestro mundo, y cuyas declaraciones públicas han llegado a un nivel inigualable de ignorancia e incompetencia. No obstante, es necesario entender que la combinación estratégica de confusión, contradicción y choque de extremos opuestos es la base para un gobierno autoritario. Todo lo que infunde una sensación de desorden y que intensifica la crisis aumenta el deseo de acciones enérgicas.

En este artículo he tratado de abrirme camino a través del pantano de temor, pánico y deseo de control para ver cómo se puede mantener un análisis crítico de la respuesta a la pandemia. Como académicos y ciudadanos, tenemos el deber de pensar más allá de la crisis, de crear aperturas y de considerar, crítica y democráticamente, cómo queremos gobernarnos a nosotros mismos. Como subraya Veena Das, es necesario que no dejemos que nuestro "amor por la sutileza y los matices de los problemas desaparezca debido a la gravedad y el apremio en una emergencia" (Das, 2020). La pandemia y la respuesta a ella exigen que reimaginemos la vida, reconstruyamos las condiciones de existencia y encontremos mejores maneras de hacer ciencia y política. Como todo compromiso con un proyecto pedagógico serio, implica reconsiderar los objetivos que deseamos.

Hoy, el temor es alimentado por cuatro fuerzas principales:

1. La modelación matemática de la enfermedad: un instrumento flexible y muy adaptable para hacer predicciones, que combina cálculos y especulaciones, a menudo basados en códigos que se mantienen en secreto y supuestos difíciles de analizar desde fuera.

2. Las políticas neoliberales: la desinversión sistemática en salud pública y atención médica, que produjo sistemas frágiles incapaces de enfrentar la crisis.

3. Los informes inquietantes de los medios: una corriente incesante de información, obsesionada por las cifras absolutas, que explota la falta de confianza en la infraestructura de salud y aumenta el temor al colapso del sistema.

4. Los anhelos autoritarios: el profundo deseo de un gobierno soberano, que obtiene placer con la destrucción e intenta empujar al mundo al borde del colapso para reconstruirlo desde cero.

Estas fuerzas tienen enorme poder para inspirar pensamientos, acciones y pasiones. Animados por la emocionante experiencia de 
presenciar la "historia en proceso", los actores e instituciones de la élite han aprovechado la oportunidad para reordenar el mundo, impulsar su agenda política en nombre de la supervivencia y moldear la vida durante los próximos años. La pandemia se ha convertido en un momento propicio para cambiar las reglas de participación y ampliar el alcance de la autoridad científica, médica y política sobre el cuerpo y la población. En una ocasión para publicar artículos y hacer declaraciones dramáticas, para sentirse relevante e importante en el mundo y disfrutar el momento siendo el centro de atención. En medio de la muerte y la destrucción, la pandemia crea oportunidades para la innovación, el dominio y la obtención de ganancias.

Esta apertura inesperada conecta a las élites de la ciencia, la política y los medios de comunicación, que lanzan información, instrucciones y mandatos que presionan con dureza nuestros cuerpos confinados, ansiosos e inquietos. La modelación matemática de la enfermedad, las políticas neoliberales, las noticias inquietantes y los anhelos autoritarios alimentan una espiral fatal centrada en el temor al colapso.

Ese temor hoy está literalmente en el aire que nos rodea; se mueve dentro y fuera de nosotros cada vez que respiramos; opera como medio de animación de nuestro intenso aislamiento e inmovilidad. El temor a la pandemia es inquietante y mentalmente agotador. Pero, para quienes abrazan ese sentimiento, tiene el poder de mantener un estado de excitación; una excitación derivada del placer secreto de arruinar algo valioso, de despilfarrar grandes recursos y de participar en un proyecto que consume todo con total dedicación. Lo que podríamos llamar la provocación de la crisis, su intensificación, expansión y totalización más allá de toda noción de utilidad, parece tan excesivo y extremo que raya en la locura. ¿Qué podría ser más peligroso, más atrevido, más excitante que un paseo por el lado salvaje, que una excursión al otro lado de la razón?

\section{CODA}

Frases melodramáticas como "vencer al virus", "ganar la guerra” y "derrotar a la oscuridad" son retóricamente poderosas y contagiosas. Nociones igualmente populares como "héroes del coronavirus" y "guerreros del confinamiento" son síntomas de híper identificación con el discurso hegemónico del poder. Todos estos términos revelan que esta pandemia es "fabulosamente textual, de principio a fin" $y$, sin embargo, al mismo tiempo carecen de una sólida fuente de simbolización, suficientemente creativa e inquietante para que lleve nuestro 
compromiso con el mundo más allá de los tropos más convencionales (Derrida, 1984). El lenguaje que hoy se nos pide adoptar, en medio de este brote, está contaminado con palabras rígidas, rancias y corruptas como el aire pútrido.

Puesto que gran parte de la respuesta actual se basa y está orientada por la modelación matemática de la enfermedad y dado que millones de vidas y medios de vida se destruyen a nuestra vista, ya no es una opción excluir las "externalidades" de una respuesta a la pandemia que carece de imaginación y que ha recurrido a la intervención más burda de todas: el pare total. Para quienes tienen trabajo permanente, un sofá cómodo y no tienen hijos que cuidar, esta interrupción imprevista puede parecer un regalo, un alivio bienvenido del mundo del capitalismo global que jamás se detiene. Pero para millones de personas que viven en lugares menos privilegiados del planeta, la pausa significa desempleo y hambre, no tiempo de descanso y de inactividad. Sin ingresos, alimentos ni acceso a cuidados de salud básicos, las personas no pasan parte del tiempo de encierro en el jardín; están desesperadas, y están muriendo.

Necesitamos con urgencia mirar más allá del virus si queremos entender la gravedad real de lo que hoy está sucediendo. ¿Cómo llegamos a este extraño espacio de pensamiento, actuación y sentimiento que normaliza los extremos y se basa en el supuesto de que la vida biológica es un valor absoluto independiente de la política? Nunca ha sido más importante insistir en que es posible otra política de la vida.

El último informe del modelo del Imperial College resume la asombrosa ceguera que ha prevalecido en esta pandemia: "No consideramos los costos sociales y económicos más amplios de la supresión, que serán elevados" (Walker et al., 2020). Se acabó el tiempo de obviar los costos de la supresión y de considerar las consecuencias de la intervención como una externalidad de la política basada en modelos.

\section{REFERENCIAS BIBLIOGRÁFICAS}

Adams, V. (2020). Disasters and capitalism and COVID-19, [http:// somatosphere.net/2020/disaster-capitalism-covid19.html/].

Arendt, H. (1951). The origins of totalitarism. Nueva York: Harcourt Brace Jovanovich.

Bagnato, A. (2020). Staying at home, [https: //www.e-flux.com/architecture/at-the-border/329404/staying-at-home/].

Baud, D. et al. (2020). Real estimates of mortality following COVID-19 Infection. The Lancet, 20(7), 773.

Beaumont, P. (2020). Coronavirus testing: How some countries got ahead of the rest? The Guardian, [https://www.theguardian.com/ 
world/2020/apr/02/coronavirus-testing-how-some-countries-germanysouth-korea-got-ahead-of-the-rest].

Buck, T. (2020). Germany's Coronavirus Anomaly. High Infection Rates But Few Deaths. Financial Times, [https: //www.ft.com/content/ c0755b30-69bb-11ea-800d-da70cff6e4d3]

Bukowski, W. (2020). La Viralita del Decoro. Controllo e Autocontrollo Sociale ai Tempi del covid-19. Giap blog, [https: //www.wumingfoundation.com /giap/2020/03/la-viralita-del-decoro-2/].

Caduff, C. (2015). The Pandemic Perhaps: Dramatic Events in a Public Culture of Danger. Berkeley: University of California Press.

Canguilhem, G. (1989). The normal and the pathological. Cambridge: MIT Press.

CDC. (2007). Interim pre-pandemic planning guidance: Community strategy for pandemic influenza mitigation in the United States, [https://www.cdc.gov/].

Chrisafis, A. (2019). French Medics Warn Health Service Is on the Brink of Collapse. The Guardian, [https: //www.theguardian.com/ world/2019/iun/11/french-medics-health-service-collapse-doctorsnurses-protest-outside-french-health-ministry-strikes].

Chulov, M. (2020). "You think we care about masks?" Anger and poverty grip Lebanese city. The Guardian, [https: //www.theguardian.com / world/2020/may/01/care-about-masks-anger-poverty-grip-lebanesecity-tripoli- coronavirus].

Daniyal, S., Sharma, S. et al. (2020). As covid-19 pandemic hits India's daily-wage earners hard, some leave city for their home towns. [https: //scroll.in/article/956779/starvation-will-kill-us-before-corona-thecovid-19-pandemic-has-hit-indias-working-class-hard].

Das, V. (2020). Facing covid-19: my land of neither hope nor despair. In covid-19 and student focused concerns: Threats and possibilities, Veena Das and Naveeda Khan, eds., American Ethnologist website, [https:// americanethnologist.org/features/collections/covid-19-and-studentfocused-concerns-threats-and-possibilities/facing-covid-19-my-landof-neither-hope-nor-despair].

Derrida, J. (1984). No apocalypse, not now. Diacritics, 14(2), 20-31.

Ferguson, N. M, Laydon,D. et al. (2020). Report 9: Impact of nonpharmaceutical interventions (NPIs) to reduce COVID-19 mortality and healthcare demand. Imperial College website, [https://www. imperial.ac.uk/mrc-global-infectious-disease-analysis/covid-19/report9-impact-of-npis-on-covid-19/].

Gebrekidan, S. (2020). For autocrats and others, corona virus is a chance to grab even more power. New York Times, [www.nytimes. $\mathrm{com} / 2020 / 03 / 30 /$ world/europe/coronavirus-governments-power. html? action $=$ click\&module $=$ Top\%20Stories\&pgtype $=$ Homepage $]$.

Graham-H., E. (2020). Wuhan facing 'wartime conditions' as global coronavirus deaths reach 724 . The Guardian, [https://www.theguardian. com/world/2020/feb/07/wuhan-facing-wartime-conditions-as-chinatries-to-contain-coronavirus].

Harris, S. y Schneider, G. S. (2020). Cash-starved hospitals and doctor groups cut staff amid pandemic. Washington Post, [https://www. washington post.com/health/starved-for-cash-hospitals-and-doctor- 
groups-cut-staff-amid-pandemic/2020/04/09/d3593f54-79a7-11eaa130-df573469f094story.html].

HRW. (2020). Bangladesh: End wave of Covid-19 Rumor arrests, [https://www.hrw.org/news/2020/03/31/bangladesh-end-wave-covid19-rumor- arrests].

Kalra, A. y Devjyot G. (2020). Indian doctors evicted over Coronavirus transmission fears, says medical body. The Wire. [https://science. thewire.in/health/indian-doctors-evicted-over-coronavirus-transmission-fears-says-medical-body/].

Kelly, A. H. (2018). Ebola vaccines, evidentiary charisma and the rise of global health emergency eesearch. Economy and Society, 1(47), 135-161.

Levenson, M. (2020). Scale of China's Wuhan Shutdown Is Believed to Be Without Precedent. The New York Times.

Mohr, M. (2020). So stark ist die Krankenhaus- Auslastung mit Corona-Patienten. MDR, [https://www.mdr.de/sachsen-anhalt/ corona-daten-update-so-stark-ist-die-krankenhaus-auslastung-coronavirus-patienten-covid-neunzehn-100.html].

Namwaya, O. (2020). Kenya Police Abuses Could Undermine Coronavirus Fight. Human Rights Watch, [https://www.hrw.org/news/2020/03/31/ kenya-police-abuses-could-undermine-coronavirus-fight].

Onder, G., Rezza, G. et al. (2020). Case-fatality rate and characteristics of patients dying in relation to COVID-19 in Italy. JAMA. E1-E2.

Qin, A. Lee, S. et al. (2020). China tightens wuhan lockdown in 'Wartime' Battle with Coronavirus. The New York Times, [https://www.nytimes. com/2020/02/06/world/asia/coronavirus-china-wuhan-quarantine.html].

Reuters. (2020). Wuhan Lockdown 'Unprecedented,' Shows Commitment to Contain Virus: WHO Representation in China. Reuters, [https:// www.reuters.com /article/us-china-health-who/wuhan-lockdown-unprecedented-shows-commitment-to-contain-virus-who-representativein-china-idUSKBN1ZM1G9].

Rushe, D. y Lauren, A. (2020). US Unemployment Rises Another $3 \mathrm{~m}$, Bringing Total to $33 \mathrm{~m}$ Since Pandemic Began. The Guardian, [https:// www.theguardian.com/business/2020/may/07/us-unemploymentjobless-coronavirus-economy].

Sharma, S. (2020). India moves big labour may law changes to limit Coronavirus impact; UP, MP, Punjab, Others Make These Changes. Financial Express, [https://www.financialexpress.com/economy/labour-reformslaws-rules-change-uttar-pradesh-up-madhya-pradesh-rajasthan-himachal-pradesh-punjab-kerala-coronavirus-reforms/1952023/].

Schultz, T. (2020). Why Belgium's death rate is so high: It counts lots of suspected covid-19 Cases. NPR, [https://www.npr.org/sections/ coronavirus-live-updates/2020/04/22/841005901/why-belgiums-deathrate-is-so-high-it-counts-lots-of-suspected-covid-19-cases].

Sullivan, R. y Kalipso, C. (2020). Urgent Call for an exit plan: The economic and social consequences of response to COVID-19 Pandemic. Centre for Global development website.

Walker, G. T., Whittaker, P. et al. (2020). The Global Impact of COVID-19 and Strategies for Mitigation and Suppression. Imperial College London, 1-19. 